\title{
Influence of North Atlantic climate variability on glacier mass balance in Norway, Sweden and Svalbard
}

\section{DAVID BROOKING BONAN, ${ }^{1}$ (1) JOHN ERICH CHRISTIAN, ${ }^{2} \mathrm{KNUT} \mathrm{CHRISTIANSON}^{2}$}

\author{
${ }^{1}$ Department of Atmospheric Sciences, University of Washington, Seattle, WA, USA \\ ${ }^{2}$ Department of Earth and Space Sciences, University of Washington, Seattle, WA, USA \\ Correspondence: David Bonan <dbonan@uw.edu>
}

\begin{abstract}
Climate variability can complicate efforts to interpret any long-term glacier mass-balance trends due to anthropogenic warming. Here we examine the impact of climate variability on the seasonal mass-balance records of $\mathbf{1 4}$ glaciers throughout Norway, Sweden and Svalbard using dynamical adjustment, a statistical method that removes orthogonal patterns of variability shared between each massbalance record and sea-level pressure or sea-surface temperature predictor fields. For each glacier, the two leading predictor patterns explain $27-81 \%$ of the winter mass-balance variability and 24 $69 \%$ of the summer mass-balance variability. The spatial and temporal structure of these patterns indicates that accumulation variability for all of the glaciers is strongly related to the North Atlantic Oscillation (NAO), with the Atlantic Multidecadal Oscillation (AMO) also modulating accumulation variability for the northernmost glaciers. Given this result, predicting glacier change in the region may depend on NAO and AMO predictability. In the raw mass-balance records, the glaciers throughout southern Norway have significantly negative summer trends, whereas the glaciers located closer to the Arctic have negative winter trends. Removing the effects of climate variability suggests it can bias trends in mass-balance records that span a few decades, but its effects on most of the longer-term mass-balance trends are minimal.
\end{abstract}

KEYWORDS: atmosphere/ice/ocean interactions, climate change, glacier fluctuations, glacier mass balance, ice and climate

\section{INTRODUCTION}

Large-scale modes of climate variability can arise in a variety of ways. Nonlinear dynamical processes intrinsic to the atmosphere can lead to daily to monthly variability that is characteristic of a random stochastic process (Hasselmann, 1976). The thermodynamic coupling of the ocean-atmosphere system has the ability to produce slower (interannual and longer) modes of climate variability due to the high thermal inertia of the ocean (Frankignoul and Hasselmann, 1977). Similarly, the response of ocean circulation to windstress forcing can lead to decadal modes of climate variability (e.g., Latif and Barnett, 1994). Regardless of their origin, these modes can exert a large influence on regional and global climate by modifying weather on interannual to multidecadal timescales (e.g., Wigley and Raper, 1990). Since accumulation and ablation are processes that are impacted by regional variations in precipitation and temperature (e. g., Bitz and Battisti, 1999; Roe, 2011), the annual or seasonal mass balance of any particular glacier can be strongly affected by climate variability.

Here we examine the influence of climate variability on the seasonal mass-balance records of ten glaciers in Norway, one glacier in Sweden and three glaciers on Svalbard using dynamical adjustment, a statistical technique based on partial least squares regression (PLS regression; Wold and others, 2001). Dynamical adjustment reveals the patterns of variability within the mass-balance records that are associated with sea-level pressure (SLP) and sea-surface temperature (SST) anomalies. Once identified, this variability can be regressed out of the records to test a key motivational question: does climate variability affect observed trends in glacier mass-balance records? This set of glaciers span a large geographic area, permitting us to investigate whether a glacier's proximity to common patterns of atmospheric and oceanic variability impacts variability in the records, and whether any long-term trends not associated with fluctuations in SLP and SST variability, such as anthropogenic warming, differ geographically.

\subsection{Glacier mass-balance records}

The variability that arises from natural fluctuations in the atmosphere and ocean has been shown to force glacier variations in several regions. Despite nearly global retreat of glaciers during the late 20th century (Oerlemans, 2005), Pohjola and Rogers (1997) linked the advance of Scandinavian glaciers during the 1990s to stronger than usual Westerlies in the wintertime and cold summertime flow, which resulted in anomalously high accumulation and low ablation. Huss and others (2010a) concluded that up to half of the recently observed glacier mass loss in the European Alps is the result of a positive phase of the Atlantic Multidecadal Oscillation (AMO), a pattern of above-normal SST in the North Atlantic which created warm summers, increasing glacier mass loss. More recently, Mackintosh and others (2017) attributed glacier advance in New Zealand from the 1980s to early2000 s to a pattern of atmospheric variability in the extratropical South Pacific that resulted in anomalous southerly winds and low regional SST.

In the era of post-industrial climate change (i.e., since 1850; Stocker, 2014), glacier mass-balance records reflect both natural and anthropogenic variations, and it is vital to 
distinguish between the two to extract and understand the response of glaciers to long-term climate changes. An externally-forced trend, such as that due to anthropogenic warming, can be masked by natural variability in the climate system (Medwedeff and Roe, 2017). And although the global aggregate of glacier-length change (Oerlemans, 2005) and glacier mass loss (Marzeion and others, 2014) has been cited as evidence of global climate change, attribution with individual records remains challenging: individual glacier mass-balance records are inherently localized climate variables, and few records are longer than several decades (e.g., Braithwaite, 2009; Zemp and others, 2015). These two characteristics make them especially susceptible to the effects of circulation-related natural variability, which can bias localized, short-term trends (e.g., Deser and others, 2012; Wallace and others, 2012).

To account for climate variability in glacier mass-balance records and to better understand the remaining trends, more regionally focused studies are needed. The Scandinavian region - the area of interest in this study - is well-suited for examining the effects of climate variability on glacier mass balance. The region is subject to a high degree of climate variability due to the strong coupling between atmospheric and oceanic processes (Marshall and others, 2001), and it is home to numerous glaciers that have multidecadal massbalance records (WGMS, 2017). Previous studies have assessed the influence of this variability on glacier massbalance records throughout the region and linked the North Atlantic Oscillation (NAO) to mass-balance variability (e.g., Nesje and others, 2000; Rasmussen and Conway, 2005; Rasmussen, 2007; Nesje and others, 2008; Marzeion and Nesje, 2012; Mutz and others, 2016). Fluctuations in other climate variables of the region, such as Arctic sea ice, have been linked to both SLP fluctuations associated with the NAO (Deser and others, 2000) and SST variations associated with the AMO (Miles and others, 2014; Li and others, 2018). Likewise, certain phases of the NAO and AMO have been shown to modulate ice melt on Greenland (Bjørk and others, 2018; Hahn and others, 2018). Dynamical adjustment is especially well-suited to assess the impacts of climate variability on glacier massbalance records in this region because it uses the SLP and SST fields directly, rather than assuming a priori that a particular mode of climate variability dominates over the others.

\subsection{Dynamical adjustment}

In recent years, dynamical adjustment has emerged as an effective tool for separating the forced and natural components in a number of climate variables. It has been used to analyze the contribution of dynamically induced variability on observed trends in snow pack (Smoliak and others, 2010; Siler and others, 2019), surface temperature (Wallace and others, 2012; Smoliak and others, 2015; Guan and others, 2015) and glacier mass balance in western North America (Christian and others, 2016). This technique has also been applied to evaluate internally generated variability within large climate model ensembles (Deser and others, 2016; Lehner and others, 2017). In this work, we use PLS-based dynamical adjustment to detect and remove dynamically induced variability in glacier mass-balance records, extending the implementation of Christian and others (2016) to a larger set of glaciers in a different geographic region.
Dynamical adjustment identifies the signature of climate variability in glacier mass-balance records under the assumption that circulation anomalies can be identified in a timevarying 'predictor' field. The predictors - in this case, SLP and SST fields - are decomposed into patterns that best explain variance in the predictand, which are individual seasonal glacier mass-balance records. Variations in SLP or SST are associated with large-scale circulation anomalies that route precipitation and temperature trajectories, which then have a direct effect on the magnitude of accumulation and ablation. It is important to note that the method does not predefine the spatial patterns of variability that drive glacier mass-balance fluctuations. The spatial patterns are emergent properties determined by the correlation between the glacier mass-balance records (i.e., the predictand) and the SLP and SST fields (i.e., the predictors). Although previous studies have assessed glacier mass-balance variability in terms of circulation anomalies, these studies often rely on climate indices (e.g., Nesje and others, 2000; Huss and others, 2010a) to express dominant modes of pressure and temperature variability (e.g., the NAO or AMO).

The method we apply takes a different approach - we identify climate variability unique to each glacier, which allows us to assess and compare the patterns that drive anomalies in individual mass-balance records. In what follows, we first describe the datasets used in this study and the PLS regression algorithm. We then analyze the raw seasonal glacier mass-balance trends and apply dynamical adjustment to identify climate variability that affects the seasonal massbalance records. Lastly, we reassess trends across the adjusted mass-balance records and discuss the implications of this work.

\section{AREA OF STUDY AND DATASETS}

\subsection{Predictands: seasonal glacier mass-balance records}

Our study includes 14 conventional glacier mass-balance records from Norway, Sweden and Svalbard (see Fig. 1). Conventional mass-balance calculations use the observed glacier area, but since the area of each glacier has evolved over the observational period, the mass-balance records may reflect both climate and glacier dynamics. This has motivated the use of the 'reference-surface' mass balance, which fixes the area of the glacier and is a better reflection of climate (Elsberg and others, 2001; Leclercq and others, 2010). However, the two methodologies have been shown to agree quite well (Elsberg and others, 2001; Huss and others, 2010b). Furthermore, a previous application in which dynamical adjustment was applied to both conventional and reference-surface mass-balance records produced similar results (Christian and others, 2016). Since the difference between the two approaches is smaller than the uncertainties in the observations, we confine ourselves to the conventional mass-balance records provided by the cognizant measuring agency. We refer to each glacier with indices organized by latitude, with G1 being the most southern glacier and G14 the most northern glacier (see Fig. 1). The Norwegian Water Resources and Energy Directorate (Kjøllmoen and others, 2017) measures the mass balance of glaciers G1-G9 and G11 and contributes these data to the World Glacier Monitoring Service (WGMS, 2017). Several of these records (G1-G9 and G11) include updates based 


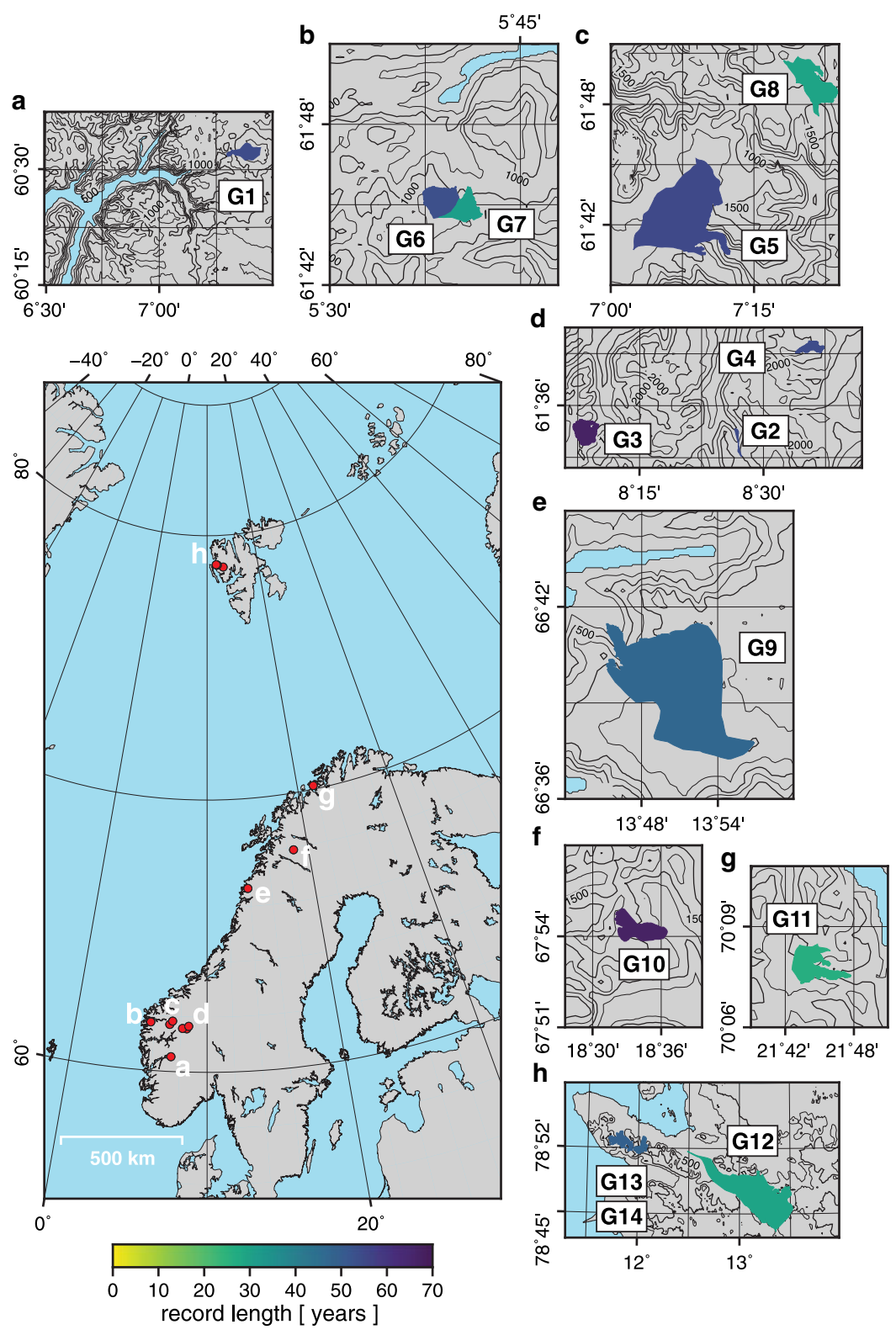

Fig. 1. Location, size and period of the glacier mass-balance records used in this study. Overview map shows the location of the glaciers used in this study. Panels $(\mathrm{a}-\mathrm{h})$ are close-ups of individual glaciers. Color shading indicates length of the record (see Table 1). Glacier extents are from the Randolph Glacier Inventory (RGI Consortium, 2017). Contours are elevation intervals of $250 \mathrm{~m}$.

on the reanalysis of Andreassen and others (2016). The massbalance record for Storgläcieren (G10) is maintained by the Bolin Centre for Climate Research (Holmlund and Jansson, 1999). The glaciers on Svalbard (G12-G14) are monitored by the Norwegian Polar Institute (NPI, 2017). Because we are interested in interannual and longer variability, we target mass-balance records long enough to capture decadal fluctuations. Table 1 shows the time period of each glacier mass-balance record considered in this study. The longest continuous records are Storbreen (G3) and Storgläcieren (G10), where the summer mass balance $\left(B_{s}\right)$, winter mass balance $\left(B_{\mathrm{w}}\right)$, and annual mass balance $\left(B_{\mathrm{a}}\right)$ are available without interruption for nearly 70 years. Although Storgläcieren's mass-balance record starts in 1946, we exclude the first 3-years of the time series as the SLP reanalysis dataset starts in 1948 . The shortest record is Langfjordjøkelen (G11), which has a mass-balance record from 1989 to 2016, but is missing data in 1994 and 1995
(Andreassen and others, 2012). Together, the glaciers we select from this region represent one of the longest regional records of glacier response to climate available in the global database (WGMS, 2017).

In addition to having such long and continuous records, this set of glaciers samples both maritime and continental climate conditions (e.g., Engelhardt and others, 2015), which allows us to understand the footprints of natural variability in different glacier regimes. Continental glaciers typically have less massbalance variability, while maritime glaciers, which depend more on precipitation, typically have more mass-balance variability (Medwedeff and Roe, 2017). Table 1 shows the mean mass-balance rates $\left(\bar{B}_{\mathrm{s}}, \bar{B}_{\mathrm{w}}\right.$, and $\left.\bar{B}_{\mathrm{a}}\right)$ for the 14 glaciers in this study. Maritime glaciers, closer to the ocean, have both high accumulation and high ablation (e.g., Ålfotbreen (G6), $\bar{B}_{\mathrm{w}}=3.62 \mathrm{~m}$ w.e. $\mathrm{a}^{-1}, \bar{B}_{\mathrm{s}}=-3.67 \mathrm{~m}$ w.e. $\left.\mathrm{a}^{-1}\right)$. Continental, or inland, glaciers often reflect a drier and colder climate, which is less dictated by variations in 
Table 1. A list of the glacier mass-balance records (G1-G14) used in this study, their latitude $\left({ }^{\circ} \mathrm{N}\right)$, elevation $(\mathrm{m} . \mathrm{a} . \mathrm{s} . \mathrm{I}$.$) , size \left(\mathrm{km}{ }^{2}\right)$, period of mass-balance record and mean summer mass balance $\left(\bar{B}_{\mathrm{s}}\right)$, winter mass balance $\left(\bar{B}_{\mathrm{w}}\right)$ and annual mass-balance $\left(\bar{B}_{\mathrm{a}}\right)$ rates during the observational period in meters-water-equivalent per year $\left(\mathrm{m}\right.$ w.e. $\left.\mathrm{a}^{-1}\right)$. For the location of each glacier, see Fig. 1.

\begin{tabular}{|c|c|c|c|c|c|c|c|c|}
\hline Glacier & ID & Latitude & Elevation & Size & Period & $\bar{B}_{\mathrm{s}}$ & $\bar{B}_{\mathrm{w}}$ & $\bar{B}_{\mathrm{a}}$ \\
\hline Rembesdalskåka & G1 & 60.53 & 1066-1854 & 17.3 & $1963-2016$ & -2.15 & 2.05 & -0.09 \\
\hline Hellstugubreen & G2 & 61.57 & $1482-2229$ & 2.9 & $1962-2016$ & -1.50 & 1.10 & -0.39 \\
\hline Storbreen & G3 & 61.57 & 1400-2102 & 5.1 & 1949-2016 & -1.77 & 1.42 & -0.35 \\
\hline Gråsubreen & G4 & 61.65 & $1833-2283$ & 2.1 & $1962-2016$ & -1.14 & 0.75 & -0.39 \\
\hline Nigardsbreen & G5 & 61.70 & 330-1952 & 46.6 & $1962-2016$ & -2.12 & 2.23 & 0.10 \\
\hline Ålfotbreen & G6 & 61.75 & 890-1368 & 4.0 & 1963-2016 & -3.67 & 3.62 & -0.05 \\
\hline Hansebreen & G7 & 61.75 & 927-1310 & 2.8 & 1986-2016 & -4.01 & 3.42 & -0.59 \\
\hline Austdalsbreen & G8 & 61.75 & $1200-1747$ & 10.6 & 1988-2016 & -2.63 & 2.17 & -0.46 \\
\hline Engabreen & G9 & 66.67 & $111-1544$ & 36.2 & 1970-2016 & -2.65 & 2.64 & -0.01 \\
\hline Storgläcieren & G10 & 67.88 & $1151-1742$ & 3.1 & 1948-2016 & -1.66 & 1.44 & -0.23 \\
\hline Langfjordjøkelen & G11 & 70.17 & 280-1050 & 3.7 & 1989-2016 & -3.03 & 2.05 & -0.97 \\
\hline Kongsvegen & G12 & 78.82 & $102-617$ & 105 & 1987-2016 & -0.77 & 0.69 & -0.07 \\
\hline Midtre Lovénbreen & G13 & 78.88 & $50-650$ & 5.4 & 1968-2016 & -1.09 & 0.70 & -0.40 \\
\hline Austre Brøggerbreen & G14 & 78.89 & $50-650$ & 6.1 & $1967-2016$ & -1.15 & 0.65 & -0.50 \\
\hline
\end{tabular}

precipitation and temperature, resulting in lower magnitude accumulation and ablation values (e.g., Hellstugubreen (G2), $\quad \bar{B}_{\mathrm{w}}=1.10 \mathrm{~m}$ w.e. $\mathrm{a}^{-1}, \quad \bar{B}_{\mathrm{s}}=-1.50 \mathrm{~m}$ w.e. $\left.\mathrm{a}^{-1}\right)$. The Arctic glaciers (G12-G14) have low mean winter massbalance rates of $0.68 \mathrm{~m}$ w.e. $\mathrm{a}^{-1}$ and mean summer massbalance rates of $-1.00 \mathrm{~m}$ w.e. $\mathrm{a}^{-1}$, typical values for glaciers in dry polar settings.

Glaciers of different sizes that are located at a variety of elevations (see Table 1) will respond to natural variability and an external forcing in different ways. The diversity in glacier size, mean mass-balance data and geographic locations further highlights the advantage of having a range of glacier mass-balance records to better understand the relationship between atmospheric and oceanic variability and glacier mass-balance fluctuations.

\subsection{Predictors: SLP and SST fields}

We use two spatiotemporal fields as predictors for glacier mass-balance variability: SLP and SST. In both cases, we use October-March and April-September averages that are similar to the winter and summer mass-balance seasons of the glacier records. The analysis is not particularly sensitive to whether we split the winter and summer averages after April or May. We restrict their spatial domain from $20^{\circ} \mathrm{N}$ to $90^{\circ} \mathrm{N}$ and from $65^{\circ} \mathrm{W}$ to $40^{\circ} \mathrm{E}$. We tested various other spatial domains, and our results are not particularly sensitive to the specific domain as long as most of the North Atlantic ocean basin is included so that large-scale circulation variability is captured.

The SLP predictor is a $2.5^{\circ} \times 2.5^{\circ}$ grid of monthly means from the NCEP-NCAR reanalysis (Kalnay and others, 1996). The SST predictor, a $1.0^{\circ} \times 1.0^{\circ}$ grid of monthly means, comes from the Met Office Hadley Centre sea ice and sea surface temperature dataset (Rayner and others, 2003). For the SST predictor, we subtract the global mean out of each month to remove the long-term warming signal associated with anthropogenic warming (Flato and others, 2014). This retains any trends unique to the North Atlantic region on interannual and multidecadal timescales. We further restrict the SST domain by removing all grid points that experience sea-ice cover (as indicated by the gray hatches in Figs 3, 5).

\section{METHODOLOGY}

\subsection{PLS-based dynamical adjustment}

Dynamical adjustment is based on PLS regression, a matrix method that combines features from principal component analysis and multiple regression (Wold and others, 2001). The goal of PLS regression is to identify structures in the predictor field, $\mathbf{X}$, that best explain the variance in the predictand, $\mathbf{Y}$. This is done iteratively, where each pass identifies a time series, $\mathbf{t}$, that expresses the amplitude of an associated spatial pattern, $\mathbf{W}$. These structures are analogous to the principal components and associated empirical orthogonal functions of a time-varying field. In PLS regression, however, $\mathbf{W}$ is determined by the correlation in time between the predictand and each grid-point of the predictor. In this way, the patterns explain maximal variance in the predictand (though not necessarily in the predictor). To extract the correlated variability, the time series $\mathbf{t}$ is projected onto $\mathbf{X}$ and $\mathbf{Y}$ to determine regression coefficients, $\mathbf{P}$ and $\beta$. The mode of variability is then regressed out of both the predictor and predictand, leaving adjusted variables:

$$
\mathbf{X}_{\mathrm{adj}}=\mathbf{X}-\mathbf{t} \mathbf{P}^{\top} \text { and } \mathbf{Y}_{\mathrm{adj}}=\mathbf{Y}-\boldsymbol{\beta} \mathbf{t}
$$

The process is then repeated with $\mathbf{X}_{\text {adj }}$ and $\mathbf{Y}_{\text {adj }}$ to identify and regress remaining patterns of predictor variability that explain variance in the predictand. After multiple iterations, the result is a decomposition of both $\mathbf{X}$ and $\mathbf{Y}$ into orthogonal modes that have been optimized to explain variance in the predictand. It should be noted that while the regression imposes orthogonality in the time series, these modes are not necessarily physically independent, as it may require more than one fixed spatial pattern to express coherent variations in SLP or SST; alternatively, a single PLS mode may capture variations due to multiple physical processes. These subsequent iterations also tend to explain less variance and eventually fail to yield any physically significant meaning. In this study, we regress only the two leading patterns out of the mass-balance time series. Modes beyond the first two explain little additional variance $(<3 \%)$ and do not substantially alter our interpretations and conclusions. For a few records, the second SLP or SST mode explains 1$5 \%$ of variance, which we note may not have physically 
significant meaning. For consistency, we choose to include the first two modes across all glaciers. For comparison, the SLP or SST predictors explain $7-11 \%$ of variance in random white noise time series (ranging 30-70 years), which provides a rough threshold for patterns that stand out of the noise. We present the PLS regression algorithm in its entirety in the Appendix, but refer the reader to Smoliak and others (2015) for a comprehensive explanation of PLS-based dynamical adjustment, including discussion on determining the number of modes to retain for a particular analysis.

PLS-based dynamical adjustment provides two useful products for interpretation: first, the patterns that explain variability in both the predictor (SLP or SST) and the predictand (seasonal glacier mass-balance records) can be interpreted as the signature of large-scale circulation variability that is correlated with mass-balance variability. As such, their spatial and temporal components can be compared with both established modes of climate variability and to the predictor patterns for other glaciers (see Section 5). Secondly, by comparing the adjusted mass-balance time series to the raw mass-balance time series, we can assess whether these signatures of climate variability have contributed to observed glacier mass-balance trends.

\subsection{Assessing glacier trends and persistence}

To evaluate the role of climate variability on glacier massbalance trends, we assess the magnitude and statistical significance of the seasonal glacier mass-balance trends both before and after dynamical adjustment. We use a twotailed $t$-test to evaluate for trend significance (Lettenmaier, 1976). Following Roe (2011), for a given glacier massbalance record, the $t$ value is given by:

$$
t=\frac{\Delta B}{\sigma} \sqrt{\frac{v-2}{12}}
$$

where $\Delta B$ is the magnitude of the total change in mass balance as estimated by a least-squares linear fit over the observational period, $\sigma$ is the standard deviation of the detrended residual and $v$ is the number of degrees of freedom. The signal-to-noise ratio $(\Delta B / \sigma)$ reveals the relationship of a trend with respect to variability, making the significance of a particular trend depends on the signal a glacier exhibits. The trend significance is also statistically dependent on the degree of persistence in the raw glacier mass-balance records, which reduces the degrees of freedom $(v)$ in the record. The majority of the glacier mass-balance records (G1-G12) we investigate, however, fall below the lag-1 autocorrelation threshold for white noise, defined by Bartlett (1946) as $(1.96) /(\sqrt{n})$. This result is consistent with the majority of glacier mass-balance records worldwide, which generally lack strong persistence on interannual timescales (Burke and Roe, 2014; Medwedeff and Roe, 2017). Hereinafter, we treat the glacier mass-balance records of G1-G12 as uncorrelated in time and assume that the degrees of freedom in each record equals the number of years in the glacier mass-balance record. To account for the weak persistence in Midtre Lovénbreen (G13) and Austre Brøggerbreen (G14), we estimate $v$ following Leith (1973), which results in $v=28$ for Midtre Lovénbreen (G13) and $v=26$ for Austre Brøggerbreen (G14) - we evaluate the trend significance accordingly. All critical $t$ values used to determine significance in this study correspond to the $95 \%$ confidence level.

\section{RESULTS}

\subsection{Raw mass-balance trends}

We begin by assessing the raw (unadjusted) winter and summer mass-balance trends, using the $t$-test as presented in the previous section (see Table 2). The summer massbalance of glaciers G1-G7 and G9 show significantly negative trends at the 95\% level. Austdalsbreen (G8) and Storgläcieren (G10) also have negative summer massbalance trends, but both are statistically insignificant. The winter mass-balance trends of G1-G10 are all statistically insignificant, and are also small in magnitude except for Austdalsbreen (G8; -0.22 m.w.e. $\mathrm{a}^{-1}$ decade $^{-1}$ ), but its short record requires a comparatively higher signal-to-noise ratio for trend significance. The glaciers situated further north (G11-G14) show more mixed tendencies. The winter mass balances are all negative, although only Langfjordjøkelen (G11) and Kongsvegen (G12) are statistically significant. Summer mass-balance trends of G11-G14 are all weakly negative and statistically insignificant. The raw mass-balance time series for G1-G14 are presented in the Supplemental Material (see Figs S1 and S2). In summary, the southern set of glaciers (G1-G10) tend to have significantly negative summer mass-balance trends and the northern set of glaciers (G11-G14) tend to have negative winter mass-balance trends, though these are only statistically significant for Langfjordjøkelen (G11) and Kongsvegen (G12). We next apply dynamical adjustment, in order to isolate and remove variability induced by largescale atmospheric or oceanic circulation, and afterward reassess trends across the adjusted mass-balance records.

\subsection{Variability in the winter mass balances}

We first consider wintertime (October-March) SLP as a predictor. We find the first two modes explain between 39 and $81 \%$ of the variance in winter mass balance (Table 3 ). Additional modes do not explain appreciable variance $(<3 \%)$. Notably, the amount of variability that SLP explains in the winter mass-balance is less (by $\sim 30 \%$ ) in the more northern glaciers (G11-G14) when compared with the more southern glaciers (G1-G10). The amount of variability explained by SLP is also higher (by 20-30\%) for the most maritime glaciers (G6-G8) when compared with the more inland glaciers (G2 and G4).

Figures 2 and 3 present the spatial pattern of variability regressed out of the winter mass balances. We focus here on the leading predictor pattern for each glacier but discuss the role of the second mode in Section 5, and provide the patterns of the second mode in the Supplementary Material (see Figs S3 and S4). The first modes of the wintertime SLP predictor patterns are shown in Fig. 2. The leading predictor pattern is nearly identical for glaciers G1-G8, which are clustered within $300 \mathrm{~km}$ of each other (Fig. 1); so we show only the mean pattern for G1-G8 in Fig. 2a. For glaciers G1-G8, G9 and G10, the leading predictor pattern has a dipole structure witha negative correlation above $60^{\circ} \mathrm{N}$ and positive correlation below $60^{\circ} \mathrm{N}$. This structure resembles the spatial signature of the NAO (Figures 2a-c; compared with Fig. 9 of Hurrell and Deser, 2010). The first mode of the wintertime 
Table 2. The seasonal glacier mass-balance trends ( $\mathrm{m}$ w.e. $\mathrm{a}^{-1}$ decade $^{-1}$ ) of the raw and adjusted time series. Values in bold are trends that are statistically significant at $95 \%$ based on a two-tailed student's $t$-test.

\begin{tabular}{|c|c|c|c|c|c|c|c|}
\hline \multirow[b]{2}{*}{ Glacier } & \multirow[b]{2}{*}{ ID } & \multicolumn{2}{|c|}{ Raw } & \multicolumn{2}{|c|}{ SLP adjustment } & \multicolumn{2}{|c|}{ SST adjustment } \\
\hline & & $B_{\mathrm{s}}$ & $B_{\mathrm{w}}$ & $B_{\mathrm{s}}$ & $B_{\mathrm{w}}$ & $B_{\mathrm{s}}$ & $B_{\mathrm{w}}$ \\
\hline Rembesdalskåka & G1 & -0.18 & 0.06 & -0.16 & -0.04 & -0.16 & 0.01 \\
\hline Hellstugubreen & G2 & -0.10 & -0.003 & -0.05 & -0.03 & -0.12 & -0.01 \\
\hline Storbreen & G3 & -0.07 & 0.001 & -0.06 & -0.03 & -0.07 & 0.004 \\
\hline Gråsubreen & G4 & -0.09 & 0.003 & -0.05 & -0.01 & -0.06 & -0.005 \\
\hline Nigardsbreen & G5 & -0.14 & 0.06 & -0.09 & -0.005 & -0.19 & 0.008 \\
\hline Ålfotbreen & G6 & -0.24 & 0.05 & -0.23 & -0.07 & -0.07 & -0.02 \\
\hline Hansebreen & G7 & -0.50 & -0.05 & -0.55 & 0.05 & 0.02 & 0.08 \\
\hline Austdalsbreen & G8 & -0.26 & -0.22 & -0.35 & -0.06 & 0.09 & -0.18 \\
\hline Engabreen & G9 & -0.16 & -0.01 & -0.14 & -0.02 & -0.11 & 0.04 \\
\hline Storgläcieren & G10 & -0.02 & 0.04 & 0.00 & -0.01 & -0.01 & 0.04 \\
\hline Langfjordjøkelen & G11 & -0.19 & -0.25 & -0.33 & -0.11 & -0.17 & -0.09 \\
\hline Kongsvegen & G12 & -0.03 & -0.09 & -0.06 & -0.07 & -0.07 & -0.10 \\
\hline Midtre Lovénbreen & G13 & -0.02 & -0.02 & -0.04 & -0.02 & -0.03 & -0.02 \\
\hline Austre Brøggerbreen & G14 & -0.02 & -0.03 & -0.04 & -0.03 & -0.002 & -0.04 \\
\hline
\end{tabular}

Table 3. Percent (\%) of summer and winter mass-balance variability explained in G1-G14 using SST and SLP as predictors. Variance explained is shown for the first mode (M1), second mode (M2) and their sum.

\begin{tabular}{|c|c|c|c|c|c|c|c|c|c|c|c|c|c|}
\hline \multirow{4}{*}{ Glacier } & \multirow{4}{*}{ ID } & \multicolumn{6}{|c|}{ SLP } & \multicolumn{6}{|c|}{ SST } \\
\hline & & \multicolumn{6}{|c|}{$\%$ Variance explained } & \multicolumn{6}{|c|}{$\%$ Variance explained } \\
\hline & & \multicolumn{3}{|c|}{$B_{\mathrm{s}}$} & \multicolumn{3}{|c|}{$B_{\mathrm{w}}$} & \multicolumn{3}{|c|}{$B_{\mathrm{s}}$} & \multicolumn{3}{|c|}{$B_{\mathrm{w}}$} \\
\hline & & M1 & M2 & Sum & M1 & M2 & Sum & M1 & M2 & Sum & M1 & M2 & Sum \\
\hline Rembesdalskåka & G1 & 23 & 17 & 40 & 62 & 14 & 76 & 29 & 11 & 40 & 20 & 20 & 40 \\
\hline Hellstugubreen & G2 & 33 & 14 & 47 & 40 & 17 & 57 & 23 & 7 & 30 & 25 & 12 & 37 \\
\hline Storbreen & G3 & 21 & 22 & 43 & 43 & 17 & 60 & 19 & 23 & 42 & 26 & 15 & 41 \\
\hline Gråsubreen & G4 & 42 & 5 & 47 & 28 & 22 & 50 & 30 & 7 & 37 & 22 & 14 & 36 \\
\hline Nigardsbreen & G5 & 35 & 6 & 41 & 57 & 14 & 71 & 21 & 3 & 24 & 26 & 19 & 45 \\
\hline Ålfotbreen & G6 & 28 & 13 & 41 & 59 & 16 & 75 & 34 & 23 & 57 & 27 & 18 & 45 \\
\hline Hansebreen & G7 & 31 & 5 & 36 & 63 & 17 & 80 & 43 & 15 & 58 & 28 & 22 & 50 \\
\hline Austdalsbreen & G8 & 28 & 8 & 36 & 67 & 14 & 81 & 45 & 24 & 69 & 42 & 12 & 54 \\
\hline Engabreen & G9 & 33 & 14 & 47 & 31 & 15 & 46 & 50 & 1 & 51 & 18 & 17 & 35 \\
\hline Storgläcieren & G10 & 34 & 15 & 49 & 50 & 19 & 69 & 26 & 17 & 43 & 29 & 13 & 42 \\
\hline Langfjordjøkelen & G11 & 17 & 15 & 32 & 17 & 33 & 50 & 29 & 20 & 49 & 40 & 12 & 52 \\
\hline Kongsvegen & G12 & 20 & 25 & 45 & 51 & 1 & 52 & 32 & 15 & 47 & 24 & 7 & 31 \\
\hline Midtre Lovénbreen & G13 & 21 & 10 & 31 & 25 & 19 & 44 & 16 & 29 & 45 & 28 & 15 & 43 \\
\hline Austre Brøggerbreen & G14 & 24 & 13 & 37 & 20 & 19 & 39 & 24 & 17 & 41 & 23 & 4 & 27 \\
\hline
\end{tabular}

SLP predictor pattern for Langfjordjøkelen (G11) is noticeably different than the southern set of glaciers (Fig. 2d), with a much less striking dipole. The leading predictor patterns of G12-G14 shows more of a tripole correlation pattern that is reminiscent of the SLP pattern typically associated with the AMO (Figure 2e; compared with Fig. 3 of Knight and others, 2006). However, this correspondence is not as close as it is for the southern glaciers and the NAO, which suggests the predictor pattern does not necessarily represent the AMO exclusively; we discuss the relationship between the predictors and established climate modes further in Section 5 .

Compared with SLP, wintertime SST explains less massbalance variability, accounting for $27-54 \%$ (Table 3 ). The first mode of the wintertime SST predictor patterns is presented in Fig. 3. The gray hatches mark areas removed from the analysis due to the influence of sea ice (see Section 2.2). The excluded points differ according to the time period of each mass-balance record; thus the hatches differ across each figure. Like SLP, the SST predictor patterns show a strong south-to-north distinction. For glaciers G1-G8, the SST predictors display a tripole spatial pattern similar to that typically associated with the NAO (Figure 3a; compared with Fig. 2 of Rodwell and others, 1999). The SST pattern of Engabreen (G9) and Storgläcieren (G10) also share these general NAO characteristics (Figures 3b, c; compared with Fig. 2 of Rodwell and others, 1999). The leading SST predictor pattern for Langfjordjøkelen (G11; Fig. 3d) is again spatially different than the SST patterns of G1-G10, as a large negative correlation pattern sits off the coast of western Europe that is not seen in the predictor patterns of G1-G10 (Figs $3 a-c)$. The leading SST patterns for the glaciers located on Svalbard (G12-G14; Fig. 3e) depict a region of positive correlation near Svalbard, along with a highly localized negative correlation pattern in the central North Atlantic Ocean basin. This structure is similar, though not 
a

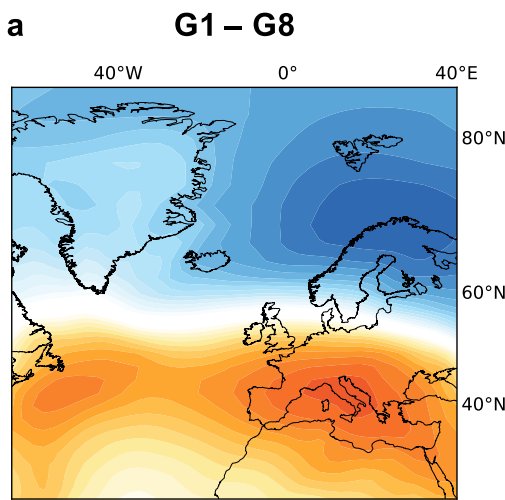

b

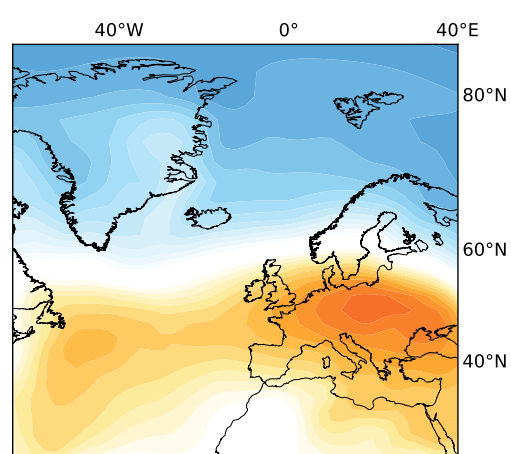

c

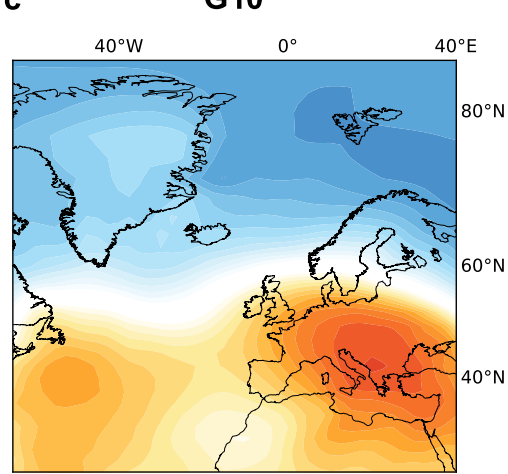

d

G11

e

G12-G14
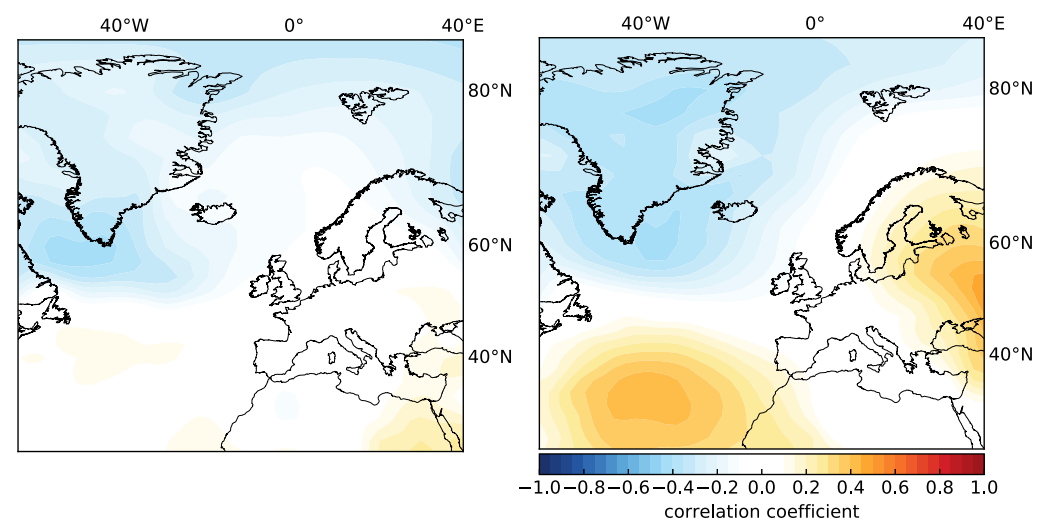

Fig. 2. Predictor patterns for the leading mode of wintertime SLP and the winter mass balance of (a) G1-G8, (b) G9, (c) G10, (d) G11 and (e) G12-G14. The patterns shown for G1-G8 and G12-G14 are both the average of each individual glacier's predictor pattern.

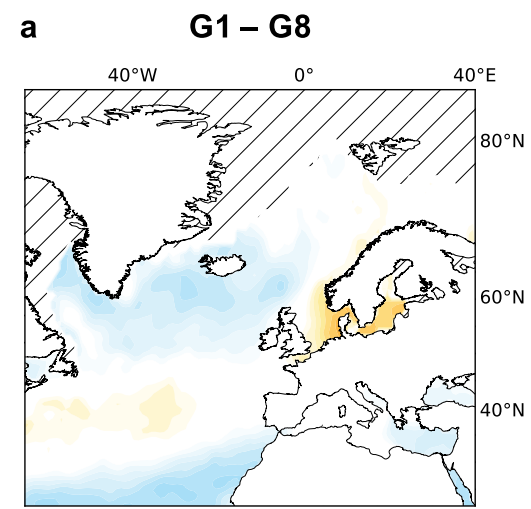

b $\quad$ G9

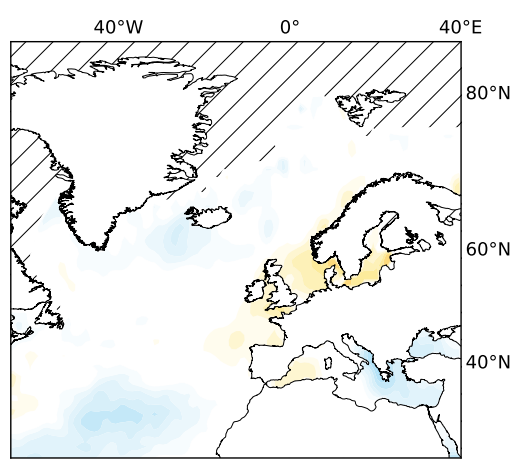

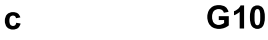

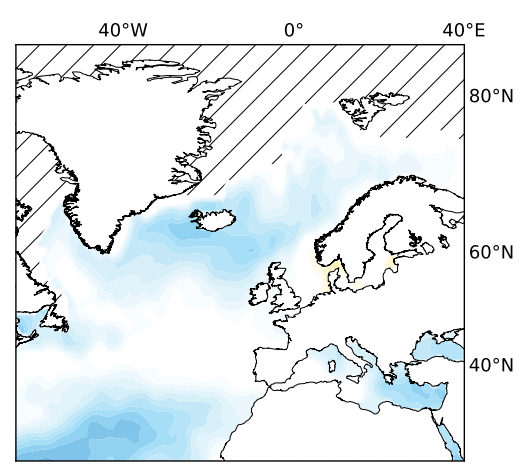

G12- G14

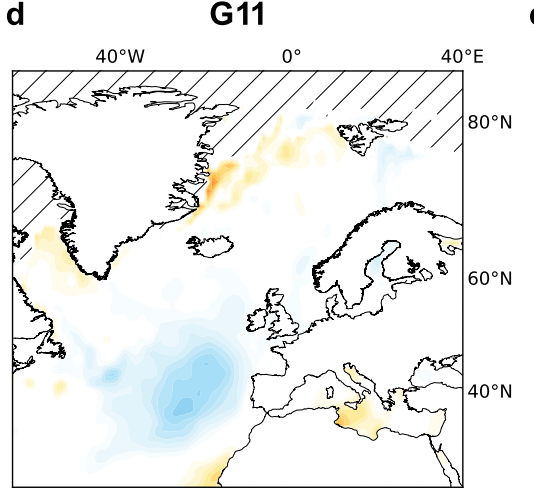

e
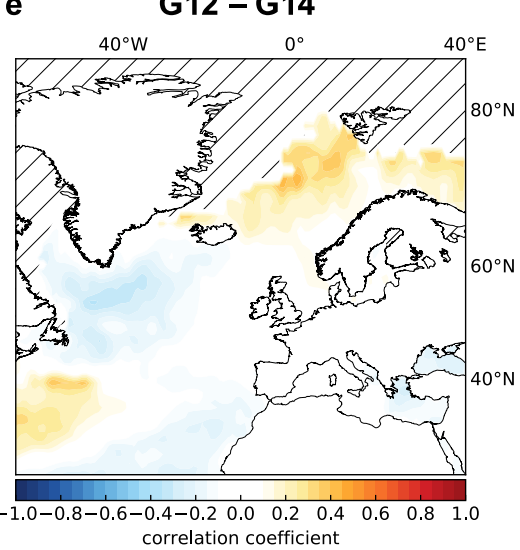

Fig. 3. Predictor patterns for the leading mode of wintertime SST and the winter mass balance of (a) G1-G8, (b) G9, (c) G10, (d) G11 and (e) G12-G14. The patterns shown for G1-G8 and G12-G14 are both the average of each individual glacier's predictor pattern. The hatches mark areas removed from the analysis due to the influence of sea ice. Note that the hatching in (d) covers a smaller area due to Langfjordjøkelen's shorter record; only grid boxes with sea ice since 1989 had to be excluded. 
identical, to the pattern of G11 (Fig. 3d) and reminiscent of the spatial signature of SST associated with the AMO (Knight and others, 2006), which physically manifests as circulation anomalies just south of Greenland near the subpolar gyre.

\subsection{Variability in the summer mass balances}

The two leading modes of the summertime (April-September) SLP and SST predictors explain between 24 and $69 \%$ of the summer mass-balance variance (Table 3 ). Circulation in the summertime is less vigorous than in the wintertime, and so, in addition to less variance explained, one may expect that summer mass balance to be more influenced by local radiative effects. Indeed, we find that the predictor patterns do not strongly resemble canonical, large-scale modes of climate variability and are likely associated with regional radiative conditions. The leading SLP and SST predictor patterns for the summer mass balances are shown in Figs 4 and 5, respectively. The second modes are again presented in the Supplemental Material (Figs S5 and S6). For G1-G10, the leading SLP predictor patterns show a center of negative correlation over the Scandinavian region (Figs $4 a-c)$. This is consistent with the persistent anti-cyclonic pressure system that tends to form over Scandinavia in the summer (Luterbacher and others, 2004). Such high-pressure systems are associated with clear skies, which result in the availability of more radiation for glacial melt. Similarly, the leading summertime SST predictor patterns (Fig. 5) show local negative correlation in the vicinity of glaciers, but are weak elsewhere. This is consistent with above-normal regional SST that would favor glacier mass loss. Alternatively, the two patterns (Figs $4 \mathrm{a}-\mathrm{C}$ and $5 \mathrm{a}-\mathrm{c}$ ) could be related: clear weather associated with a persistent high-pressure system would create above-normal SST and enhance incident short-wave radiation on the glaciers in the region.

\subsection{Adjusted mass-balance trends}

Our analyses show that between 24 and $81 \%$ of seasonal glacier mass-balance variability can be explained by variability in SLP and SST (Table 3). We next evaluate whether these circulation patterns are responsible for some or all of the observed trends in the mass-balance records. Following Smoliak and others (2010), we do this by evaluating the trends in the time series after the variability associated with the circulation has been regressed out (shown in Table 2). To illustrate the procedure, Fig. 6 shows the effect of removing, separately, SLP and SST variability on the summer massbalance of a long-term record, Storbreen (G3) and the winter mass-balance of a short-term record, Langfjordøkelen (G11). For the long-term record, though $\sim 43 \%$ of the summer massbalance variability can be explained by SLP or SST variability (Table 3), the significantly negative trend remains largely unchanged (Fig. 6a). Conversely, with a short-term record, the variance explained by SLP or SST $(\sim 50 \%)$ substantially alters the magnitude of the trend (Fig. 6b). The adjusted time series of all of the glaciers are also directly presented in the Supplemental Material (see Figs S1 and S2).

Generally, the summer mass-balance trends do not substantially change after SLP adjustment, although there are a few exceptions. The trends of G1, G3, G5-7 and G9 do remain significantly negative at the $95 \%$ level, though most trends become slightly less negative. However, the summer mass-balance trends of Hellstugubreen (G2) and Gråsubreen (G4) remain negative, but drop in magnitude and become statistically insignificant. Notably, the summer mass-balance trends of Austdalsbreen (G8) and Langfjordjøkelen (G11), which both have short massbalance records ( 30-years), become significantly negative after SLP adjustment; their negative trends increase in magnitude by $\sim 50 \%$. The summer mass-balance trends of G12-G14 remain negative and insignificant, but their trends increase in magnitude. In the winter season, despite accounting for $39-81 \%$ of the winter mass-balance variability for G1-G10, SLP anomalies have little effect on the longterm trends; the winter mass-balance trends of G1-G10 remain insignificant, though most trends increase in magnitude. The negative winter mass-balance trend of Langfjordjøkelen (G11), which again has a short massbalance record, loses statistical significance after SLP adjustment removes $\sim 50 \%$ of its negative trend (see Fig. $6 \mathrm{~b}$ ). The significantly negative winter mass-balance trend of Kongsvegen (G12) remains significantly negative after adjustment with SLP variance. The insignificant negative winter mass-balance trend of Austre Brøggerbreen (G14) is essentially unchanged, but becomes statistically significant, having lower overall variance. Lastly, the insignificant negative trend of Midtre Lovénbreen (G13) remains insignificant and changes little in magnitude after SLP adjustment.

When using SST as a predictor for glacier mass-balance variability, the adjusted mass-balance trends also remain broadly similar to the raw mass-balance trends with some exceptions. The summer mass-balance trends of G1-G3, G5 and G9 remain significantly negative and change little in magnitude (see Fig. 6a). In contrast, the summer massbalance trends of G4, G6, and G7 become insignificant and the magnitude of their trends change substantially after SST adjustment. The summer mass-balance trend of both Hansebreen (G7) and Austdalsbreen (G8) change sign. As with SLP, the summer mass-balance trends of G12-G14 remain insignificant and the magnitude of each changes little with SST adjustment. In the winter season, the trends of G1-G9 remain insignificant and the positive winter mass-balance trend of Storgläcieren (G10) becomes significantly positive after SST adjustment. The significantly negative winter mass-balance trend of Kongsvegen (G12) remains and the negative winter mass-balance trend of Austre Brøggerbreen (G14) becomes significantly negative. As with the SLP adjustment, the winter mass-balance trend of Langfjordjøkelen (G11) is reduced by $>50 \%$ and loses statistical significance (see Fig. 6b). Lastly, the winter massbalance trend of Midtre Lovénbreen (G13) remains negative and insignificant after SST adjustment.

\section{DISCUSSION}

Using dynamical adjustment, we identified and removed variability associated with SLP and SST anomalies from the seasonal mass-balance records of 14 glaciers throughout Norway, Sweden and Svalbard. Our study adds to an already extensive literature (e.g., McCabe and Fountain, 1995; Pohjola and Rogers, 1997; Bitz and Battisti, 1999; Nesje and others, 2000; Rasmussen and Conway, 2005; Rasmussen, 2007; Nesje and others, 2008; Huss and others, 2010a; Marzeion and Nesje, 2012; Trachsel and Nesje, 2015; Mutz and others, 2016; Christian and others, 2016) on the relationship between atmospheric and 


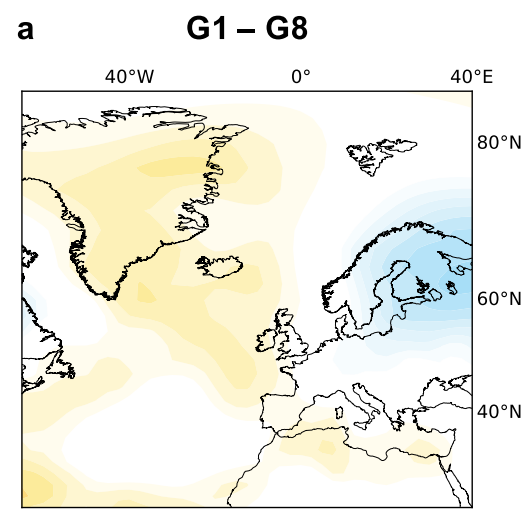

b $\quad$ G9

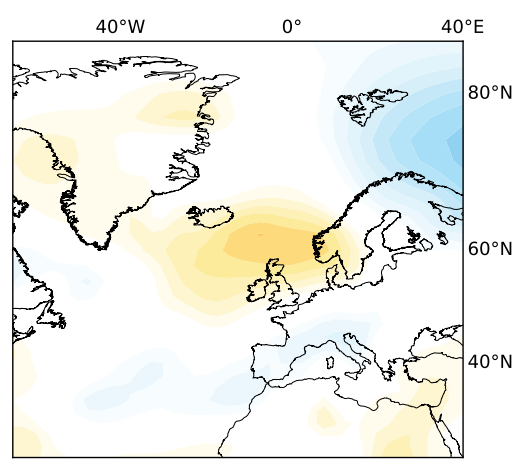

c $\quad \mathbf{G 1 0}$

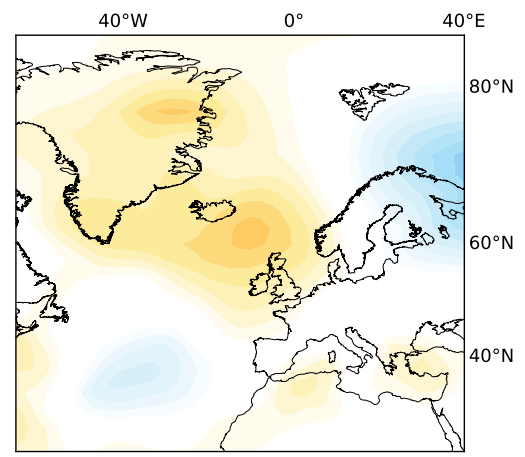

d

\section{G11}

e
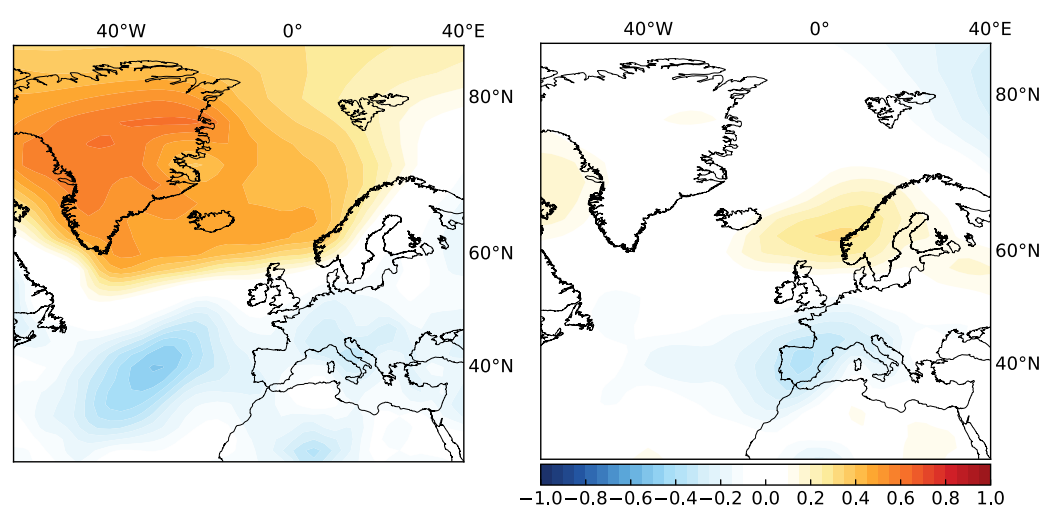

correlation coefficient

Fig. 4. Predictor patterns for the leading mode of summertime SLP and the summer mass balance of (a) G1-G8, (b) G9, (c) G10, (d) G11 and (e) G12-G14. The patterns shown for G1-G8 and G12-G14 are both the average of each individual glacier's predictor pattern.

a

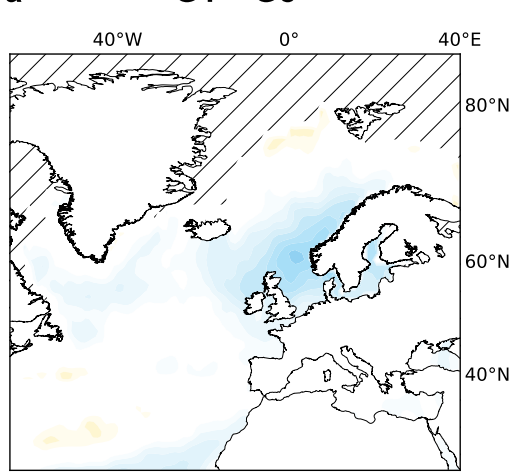

b

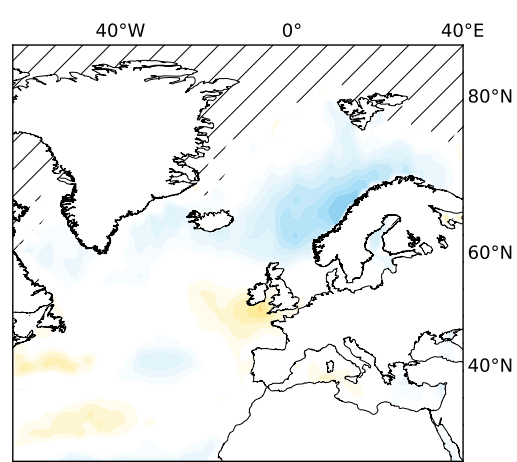

C

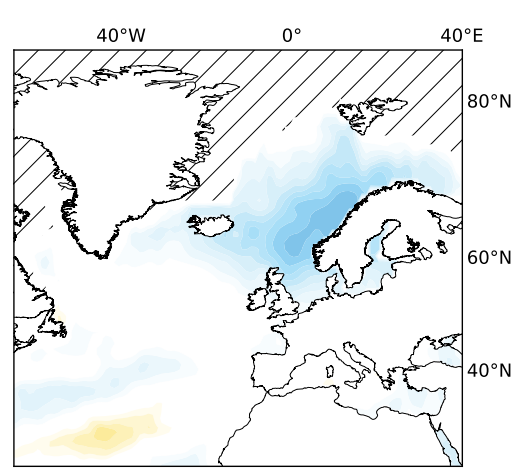

d

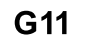

e

G12 - G14
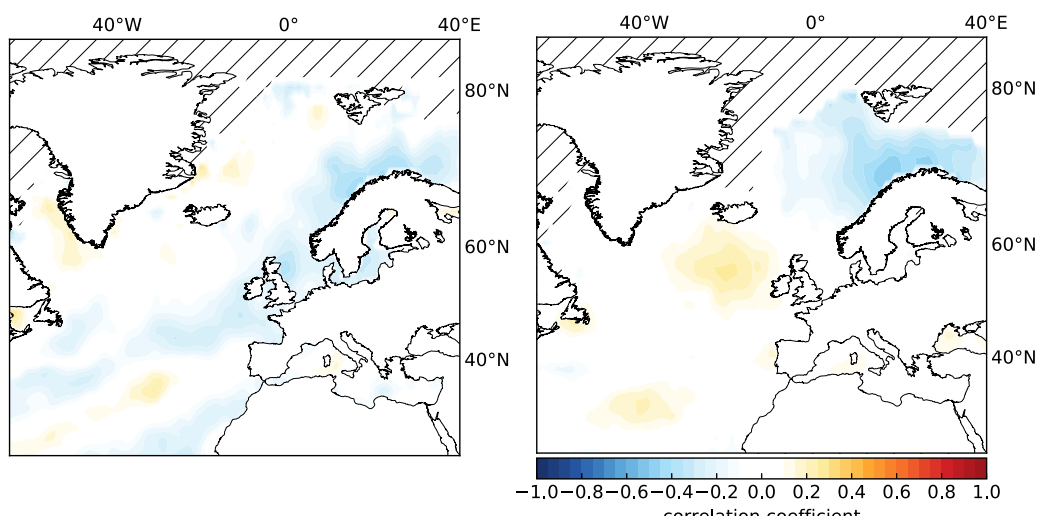

Fig. 5. Predictor patterns for the leading mode of summertime SST and the summer mass-balance of (a) G1-G8, (b) G9, (c) G10, (d) G11 and (e) G12-G14. The patterns shown for G1-G8 and G12-G14 are both the average of each individual glacier's predictor pattern. The hatches mark areas are removed from the analysis due to the influence of sea ice. 
a

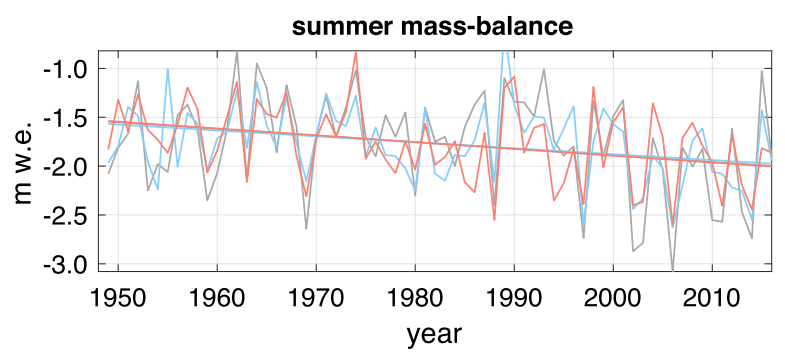

b

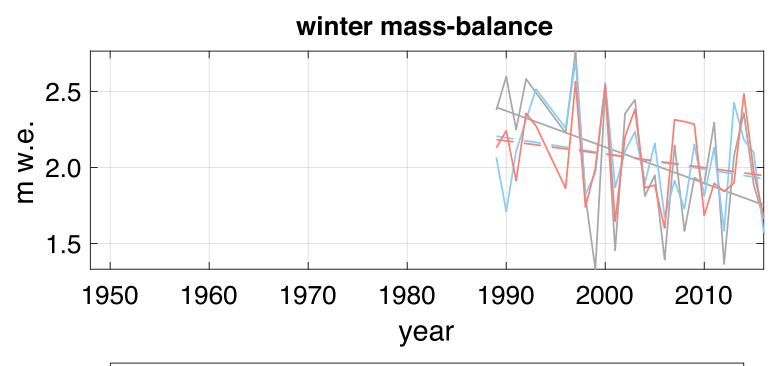

Fig. 6. The raw (gray), adjusted with SLP variability (blue) and adjusted with SST variability (red) summer mass-balance time series for (a) Storbreen (G3) and the winter mass-balance time series for (b) Langfjordjøkelen (G11). The lines represent a least squares linear fit of each time series. The dashed line denotes an insignificant trend and the solid line denotes a significant trend based on the $t$-test presented in Section 3 .

oceanic circulation and glacier mass balance by identifying patterns of climate variability that best explain massbalance variability for each glacier. These analyses identify the influence of two prominent modes of variability in the North Atlantic region (i.e., the NAO and AMO) based on the spatial patterns in the leading modes of the predictor fields in the winter adjustments. However, the influences of each are regionally distinct: predictor patterns resembling the NAO drive accumulation variability for the southern glaciers (G1-G10), while patterns spatially resembling the AMO seem to drive accumulation variability for the more northern glaciers (G11-G14). In what follows, we first summarize circulation anomalies that are associated with the canonical $\mathrm{NAO}$ and AMO patterns. Then we explore their expression in the winter mass-balance records by comparing the PLS time series with the NAO and AMO indices to quantitatively assess the drivers of accumulation variability. Lastly, we place the results of our study in a broader context by considering the implications of trend changes associated with dynamically induced variability.

\subsection{Modes of climate variability}

The NAO is a mode of variability that expresses variations in the strength and orientation of the Westerlies, which control moisture and heat transport trajectories in the North Atlantic region (Hurrell, 1995). The mechanisms creating these variations remain under debate (e.g., Visbeck and others, 2001; Hurrell and Deser, 2010), but a positive winter NAO phase is associated with low pressure across the high latitudes of the North Atlantic, strengthening the Icelandic low, and high pressure off the coast of western Europe, strengthening the Azores high. This increased south-to-north pressure gradient, drives storm tracks farther north, causing above-normal precipitation over northern Europe and Scandinavia. A negative winter NAO phase is associated with the opposite pressure anomalies over these regions, sending storm tracks farther south and creating below-normal precipitation over northern Europe and Scandinavia (Hurrell and others, 2003).

Another dominant mode of variability in the region, the $\mathrm{AMO}$, is a coherent pattern of SST variability that is often ascribed a multidecadal signature of 60-80 years, though it is important to note that these anomalies also have substantial power at interannual timescales (see Burke and Roe, 2014). There is ongoing debate about the origins of this variability and whether it arises primarily through the influence of internal atmospheric variability or through changes in ocean circulation (e.g., Clement and others, 2015; O'Reilly and others, 2016). Recent work suggests that the dynamic coupling between atmospheric and oceanic circulations is fundamental to the AMO (Wills and others, 2019). Regardless of the underlying mechanisms, the AMO is principally defined in terms of the spatially averaged SST anomalies in the North Atlantic basin $\left(0-60^{\circ} \mathrm{N}, 0-80^{\circ} \mathrm{W}\right)$, with a positive (negative) AMO phase identified by above (below) normal SST. AMO variability contributes to anomalously warmer or cooler summers over North America and western Europe (Sutton and Hodson, 2005), changes in northern hemispheric mean surface temperature (Knight and others, 2006) and Arctic sea-ice variability (Miles and others, 2014; Li and others, 2018) through the basin-wide redistribution of heat and mass. In the wintertime, a positive AMO phase and above-normal surface temperatures may elevate the rain-snow line, thereby altering the amount of snow accumulation on glaciers.

\subsection{Mass-balance variability}

The leading SLP and SST predictor patterns for the winter mass balance of the southern glaciers (G1-G10), resemble the spatial signature of the NAO (Figs $2 \mathrm{a}-\mathrm{C}$ and $3 \mathrm{a}-\mathrm{C}$ ). The relationship between the $\mathrm{NAO}$ and accumulation variability has been well-documented (e.g., Pohjola and Rogers, 1997; Nesje and others, 2000; Rasmussen, 2007; Nesje and others, 2008; Mutz and others, 2016) and it can be interpreted in the light of the storm-track and precipitation relationships described above. The leading SLP and SST predictor patterns of the winter mass-balance of the northern glaciers (G11G14) exhibit a more AMO-like spatial structure, with a polarity that indicates anti-correlation with the AMO index (Figs $2 \mathrm{~d}$, e and $3 \mathrm{~d}, \mathrm{e})$. However, this pattern is not identical to the $\mathrm{AMO}$ and may actually be a blend of different physical mechanisms. For instance, there are also localized positive SST correlations off the coast of Svalbard, suggesting that local SST variations may result in changes to nearby surface temperatures over land. During the winter season, this may allow for stronger storm systems, and thus more accumulation. The influence of the AMO on winter massbalance variability for the glaciers on Svalbard (G12-G14) is consistent with the spatial extent of the AMO, which influences sea-ice variability near Svalbard (e.g., Day and others, 2012; Miles and others, 2014; Li and others, 2018). A mechanistic understanding of how the AMO impacts glacier mass balance in the Arctic may be difficult to partition from circulation variability associated with the NAO. In fact, Wills and others (2019) propose that interannual variability, such as the $\mathrm{NAO}$, is a key driver of the AMO, which suggests that the two 


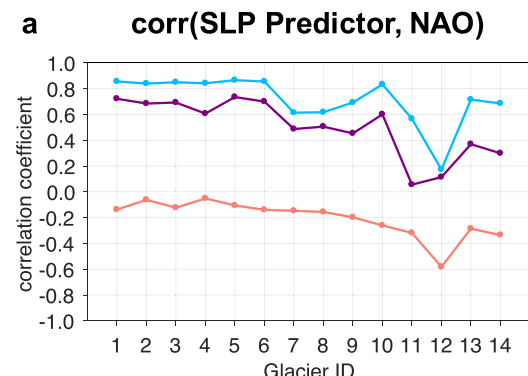

c

Leading time series

Glacier ID

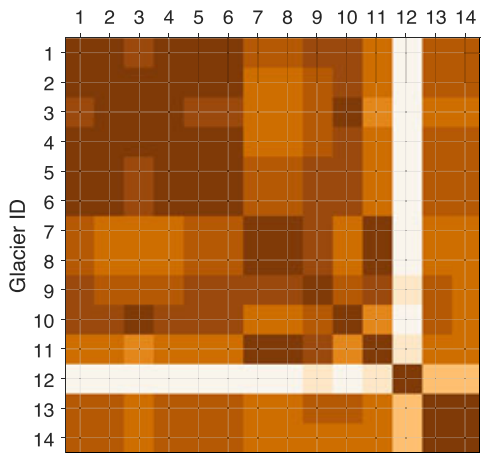

b corr(SLP Predictor, AMO)

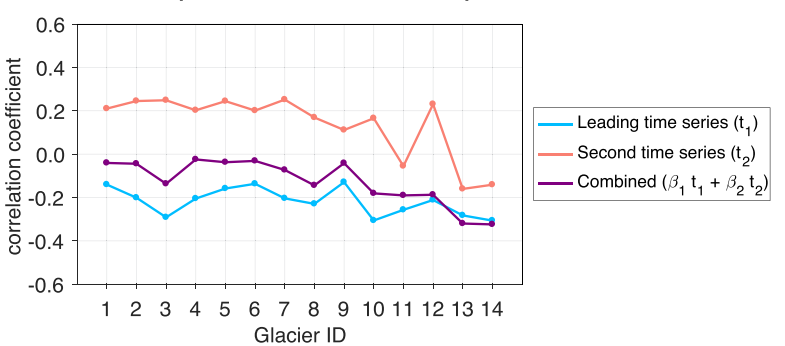

d

Second time series

Glacier ID

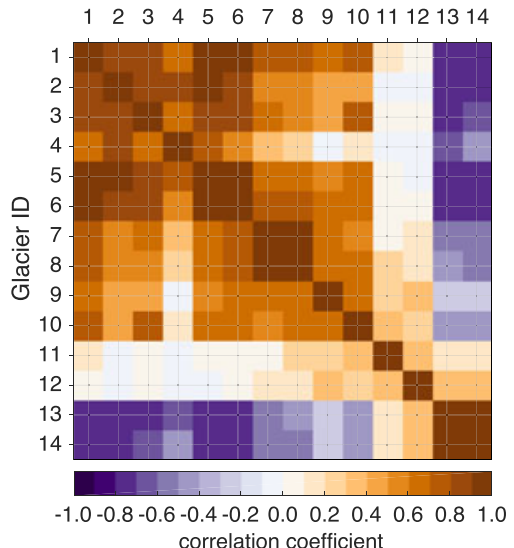

e

\section{Combined time series}

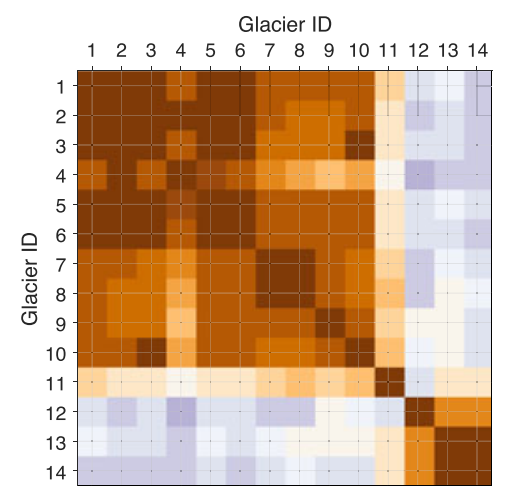

Fig. 7. $(a, b)$ Correlations between climate indices and the SLP predictor time series identified by dynamical adjustment of each winter massbalance record. Correlations are shown for the two leading time series alone ( $\mathbf{t}_{1}$ and $\left.\mathbf{t}_{2}\right)$, and their weighted combinations $\left(\beta_{1} \mathbf{t}_{1}\right.$ and $\left.\beta_{2} \mathbf{t}_{2}\right)$. (a) Winter (October-March) NAO index and SLP predictors. (b) Winter AMO index and SLP predictors. (c-e) Inter-glacier correlations of the leading PLS time series (c), the second time series (d) and the combined time series (e). In this case, the second mode helps differentiate the signals of dynamically induced variability between southern and northern glaciers.

modes are intimately related. However, it is worth noting the correlations suggest a negative tendency on winter mass balance occurs when there is a positive AMO phase (above-normal SST). Yet, a positive AMO is associated with an increase in both precipitation and surface temperatures, suggesting that questions remain about the relative importance of accumulation versus winter melt events on high-latitude glaciers and ice sheets.

Since the predictor patterns are not identical to the NAO or $\mathrm{AMO}$, the variability removed from the seasonal massbalance records likely represent a combination of different modes of climate variability. The PLS time series associated with these spatial patterns can be compared with the temporal indices for the $\mathrm{AMO}$ and NAO to further assess the primary drivers of glacier mass-balance variability. In the following, we use October-March averages of monthly NAO and AMO indices from NOAA's Climate Prediction Center (1950-present; Barnston and Livezey, 1987) and Earth System Research Laboratory (1948-present; Enfield and others, 2001), respectively. Figure 7 shows temporal correlations between SLP predictors and the NAO index (Fig. 7a), and SLP predictors and the AMO index (Fig. 7b). Correlations are shown for the two leading PLS time series alone $\left(\mathbf{t}_{1}\right.$ and $\left.\mathbf{t}_{2}\right)$, and their linear combinations $\left(\beta_{1} \mathbf{t}_{1}+\right.$ $\beta_{2} \mathbf{t}_{2}$ ), the latter of which are the signals ultimately regressed out of the mass-balance records. In general, correlations between the leading PLS time series and the NAO are stronger than with $\mathrm{AMO}$; however, these correlations also show a slight geographic trend of greater influence of the NAO in the south and an anti-correlation with the AMO in the north, especially with the combined modes. For comparison, correlation of the NAO with wintertime precipitation from Norwegian station data is similar ( 0.70; Hurrell, 1995), which adds confidence to the interpretation that the leading PLS mode captures the precipitation signal associated with large-scale atmospheric variability. The remaining variability may be due to local processes (avalanching or wind redistribution) or measurement error. It should be borne in mind that correlations are less robust for the shorter ( 30-year) records of G7, G8, G11 and G12.

The existence of moderate-to-strong correlations across latitudes for both the NAO and AMO suggests that the variability in any mass-balance record is not fully described by a single climate index, but may have multiple origins in the coupled ocean-atmosphere system of the North Atlantic. A combined regression of multiple independent modes, as is done with dynamical adjustment, provides a way to capture this blended variability and also the differing signatures between glaciers. Figures $7 \mathrm{c}-\mathrm{e}$ displays correlations of the winter SLP time series between pairs of glaciers, again showing the two leading modes alone (Figs 7c-d) and their combination (Fig. 7e). The inter-glacier correlations demonstrate the importance of the second mode for these adjustments: In Fig. 7c, correlations are strong between nearly all glaciers, consistent with some influence of the NAO throughout the region (e.g., Fig. 7a); however, correlations for Fig. 7d have marked differences for southern and northern glaciers. These groups of correlation and anti-correlation also manifest in the combined time series, shown in Fig. 7e. Thus, along with explaining an additional $15-20 \%$ of variance in each record (Table 2), these second modes clarify the geographic dependence of mass-balance variability. 
These relationships are generally less clear when using SST as a predictor (see Fig. S7 in the Supplemental Material). Because SLP and SST generally have different spatial patterns of variation, the variability identified by dynamical adjustment is not likely to be identically partitioned between the leading modes. The relationships may also be less clear simply because SST is a less robust predictor for mass-balance variability: dynamical adjustments with SST explain less variance than with SLP in nearly all cases (Table 3). The need to remove the global-mean signal as well as any grid-points with sea ice make SST a less-direct and less-expansive indicator of circulation variability for this application. Furthermore, reliably removing the externally forced anthropogenic signal within SST is challenging (e.g., Wills and others, 2018) - subtracting the global-mean value at each time step may leave residual regional warming trends. While it can provide a useful check for consistency with SLP adjustments (e.g., noting the influence of $\mathrm{AMO} / \mathrm{NAO}$ indices in both), we have more confidence in our interpretations of the SLP predictor patterns and time series identified by dynamical adjustment.

\subsection{Adjusted trends}

After the patterns of variability described above have been regressed out of the original mass-balance records, the adjusted records may more directly manifest long-term trends. Largely, the negative summer mass-balance trends of G1-G9 remain after SST and SLP adjustments, which suggests that the trends are not associated with dynamically induced variability. There are, however, a few notable exceptions. For example, the summer mass-balance trends of Ålfotbreen (G6) and Hansebreen (G7), the two most maritime glaciers in this study, remain negative but become insignificant after adjustment with SST (Table 2). Similarly, the summer mass-balance trends of Hellustubreen (G2) and Gråsubreen (G4) remain negative but become insignificant after SLP adjustment (Table 2). These results suggest that some of the negative summer mass-balance trend may be the result of SST and SLP anomalies not associated with anthropogenic warming. Of course, it is certainly possible that these anomalies may themselves be the forced response, which would suggest that the negative trend will continue. Removing these anomalies make our analysis of any remaining trends a conservative estimate of the anthropogenic signal. Additionally, given the caveats of using SST as a predictor, changes to trend significance due to SST adjustment alone should be interpreted with caution. The negative summer mass-balance trends of Austdalsbreen (G8) and Langfjordjøkelen (G11), which both have short massbalance records, increase in magnitude and gain statistical significance after SLP adjustment. However, Austdalsbreen is calving into a regulated lake, so caution should be applied when interpreting these trend results since its ablation is influenced to some extent by this regulation (Fleig and others, 2013). Still, this highlights that short-term massbalance records can be especially susceptible to biases from variability in atmospheric circulation.

For the winter season, the mass-balance trends remain insignificant in the southern group (G1-G9) after both SST and SLP adjustments, though most trends do become slightly more negative. This result indicates that circulation variability while explaining between 27 and $81 \%$ of the winter massbalance variability (Table 3 ), is not substantially biasing or masking any strong underlying trends. The positive winter mass-balance trend of Storgläcieren (G10), which is insignificant in the raw record, does become significantly positive after adjustment with SST, although not with SLP (Table 2). However, this significance arises mainly through the reduction of variance; the very minor change in magnitude suggests that SST variability is not substantially biasing Storgläcieren's (G10) trend. The geographic tendency of negative winter mass-balance trends for the more Northern glaciers remains after SLP and SST adjustment. The negative winter mass-balance trend of Langfjordjøkelen (G11) is greatly reduced by both SLP and SST adjustment and loses statistical significance, suggesting that climate variability is biasing the trend in its short winter mass-balance record (see Fig. 6b). Lastly, the insignificant winter mass-balance trend of Austre Brøggerbreen (G14) becomes significantly negative once variability from either SLP or SST is removed. However, the tiny change in magnitude suggests that climate variability is not substantially biasing the winter mass-balance trend of Austre Brøggerbreen.

\section{SUMMARY AND CONCLUSION}

A key challenge in climate science is quantifying the effects of internal variability on climate records (e.g., Hawkins and Sutton, 2009; Deser and others, 2012). Glacier retreat is a prominent and tangible manifestation of a warming world and the regional attribution is quite robust (e.g., Roe and others, 2017). The mass-balance record of any glacier, however, can reflect anthropogenic changes as well as a high degree of variability induced by natural fluctuations of the climate system. Indeed, this means that the variability in any one record may be the result of multiple processes that drive anomalies in accumulation or ablation. This leads to an important prerequisite step before the mass loss of any individual glacier can be attributed to anthropogenic warming: the patterns of large-scale atmospheric and ocean circulation that drive glacier mass-balance variability must be identified and their effect on glacier mass-balance quantified. This work identified that glaciers throughout Norway, Sweden and Svalbard are influenced by the NAO, which is associated with the routing and intensity of winter storms consistent with several previous studies (e.g., Pohjola and Rogers, 1997; Nesje and others, 2000; Rasmussen, 2007; Nesje and others, 2008; Marzeion and Nesje, 2012; Trachsel and Nesje, 2015). However, dynamical adjustment also revealed that the glaciers residing farther north show progressively more influence of AMO-like anomalies, which suggests that while the NAO is the primary driver of glacier mass-balance variability in the region, both modes of climate variability act to drive anomalies in accumulation. As a large portion of winter mass-balance variability (between 27 and 81\%) in this region is driven by patterns reminiscent of these two modes of climate variability, predictions of glacier change may be limited by predictability of the $\mathrm{NAO}$ and $\mathrm{AMO}$.

Analysis of trends in the raw and adjusted mass-balance time series is another key result of this study. The glaciers located in southern Norway tend to have significantly negative summer mass-balance trends, whereas the glaciers located farther north tend to have significantly negative winter mass-balance trends. After dynamical adjustment, these seasonal trends largely remain. This suggests that longterm mass-balance trends across the majority of the glaciers 
in Norway, Sweden and Svalbard has little to do with circulation variability, which stands in contrast to some analyses for glaciers in the Alps, where approximately half of the massbalance trend is attributable to the AMO (Huss and others, 2010a). The exceptions - where dynamically induced variability more substantially affects mass-balance trends - tend to be those glaciers with shorter mass-balance records or that reside in more maritime climates. This demonstrates the challenges associated with interpreting trends in any single mass-balance record, especially on short timescales. Dynamical adjustment, however, is an effective tool for quantifying these effects as it identifies large-scale circulation patterns that are correlated with glacier mass balances without assuming a relationship to a predefined climate index. Identifying the signature of natural variability will always be a vital step in interpreting trends in glacier mass-balance records. Similar analyses in other regions with multidecadal mass-balance records, such as the Alps, may lead to a more robust understanding of the roles of circulation variability and of anthropogenic forcing on glacier mass balance. Even where long-term glacier mass-balance records are not available, partitioning natural variability from the forced response remains important, and previous applications of dynamical adjustment to temperature and precipitation measurements suggest that it could be applied to investigate the underlying drivers of glacier change in such settings as well.

\section{SUPPLEMENTARY MATERIAL}

The supplementary material for this article can be found at https://doi.org/10.1017/jog.2019.35

\section{ACKNOWLEDGMENTS}

This work benefited from insightful discussions with Kyle Armour, Cecilia Bitz, and Jack Kohler. We thank Gerard Roe for detailed comments on a draft of this manuscript and Nicholas Siler for offering guidance on the statistical technique. We also thank the Editor, Carleen Tijm-Reijmer and two anonymous reviewers for comments that greatly improved the manuscript. DBB was supported by startup funds from $\mathrm{KC}$ at the University of Washington. JEC was supported by the National Science Foundation Graduate Research Fellowship Program (DGE-1256082).

\section{REFERENCES}

Andreassen LM, Nordli $\varnothing$, Rasmussen A and Melvold K (2012) Langfjordjøkelen, a rapidly shrinking glacier in northern Norway. J. Glac., 58(209), 581-593 (doi: 10.3189/2012JoG1)

Andreassen LM, Elvehøy H, Kjøllmoen B, and Engeset RV (2016) Reanalysis of long-term series of glaciological and geodetic mass balance for 10 Norwegian glaciers. The Cryosphere, 10(2), 535-552 (doi: 10.5194/tc-10-535-2016)

Barnston AG and Livezey RE (1987) Classification, seasonality and persistence of low-frequency atmospheric circulation patterns. Mon. Weather Rev., 115(6), 1083-1126 (doi: 10.1175/15200493(1987)115<1083:CSAPOL>2.0.CO;2)

Bartlett MS (1946) On the theoretical specification and sampling properties of autocorrelated time-series. J. Royal Stat. Soc., 8(1), 27-41 (doi: 10.2307/2983611)

Bitz C and Battisti D (1999) Interannual to decadal variability in climate and the glacier mass balance in Washington, western Canada, and Alaska. J. Clim., 12(11), 3181-3196 (doi: 10.1175/1520-0442(1999)012<3181:ITDVIC > 2.0.CO;2)
Bjørk AA and 13 others (2018) Changes in Greenland's peripheral glaciers linked to the North Atlantic Oscillation. Nat. Clim. Change, 8(1), 48 (doi: 10.1038/s41558-017-0029-1)

Braithwaite RJ (2009) After six decades of monitoring glacier mass balance we still need data but it should be richer data. Ann. Glac., 50(50), 191-197 (doi: 10.3189/172756409787769573)

Burke EE and Roe GH (2014) The absence of memory in the climatic forcing of glaciers. Clim. Dyn., 42(5-6), 1335-1346 (doi: 10.1007/s00382-013-1758-0)

Christian JE, Siler N, Koutnik M and Roe G (2016) Identifying dynamically induced variability in glacier mass-balance records. J. Clim., 29(24), 8915-8929 (doi: 10.1175/JCLI-D-16-0128.1)

Clement A and 6 others (2015) The Atlantic Multidecadal Oscillation without a role for ocean circulation. Science, $\mathbf{3 5 0}$ (6258), 320-324 (doi: 10.1126/science.aab3980)

Day J, Hargreaves J, Annan J and Abe-Ouchi A (2012) Sources of multi-decadal variability in Arctic sea ice extent. Environ. Res. Lett., 7(3), 034011 (doi: 10.1088/1748-9326/7/3/034011)

Deser C, Walsh JE and Timlin MS (2000) Arctic sea ice variability in the context of recent atmospheric circulation trends. J. Clim., 13 (3), 617-633 (doi: 10.1175/1520-0442(2000)013<0617: ASIVIT > 2.0.CO;2)

Deser C, Phillips A, Bourdette V and Teng H (2012) Uncertainty in climate change projections: the role of internal variability. Clim. Dyn., 38(3-4), 527-546 (doi: 10.1007/s00382-010-0977-x)

Deser C, Terray L and Phillips AS (2016) Forced and internal components of winter air temperature trends over North America during the past 50 years: Mechanisms and implications. J. Clim., 29(6), 2237-2258 (doi: 10.1175/JCLI-D-15-0304.1)

Elsberg D, Harrison W, Echelmeyer K and Krimmel R (2001) Quantifying the effects of climate and surface change on glacier mass balance. J. Glac., 47(159), 649-658 (doi: 10.3189/ 172756501781831783)

Enfield DB, Mestas-Nuñez AM and Trimble PJ (2001) The Atlantic Multidecadal Oscillation and its relation to rainfall and river flows in the continental US. Geophys. Res. Lett., 28(10), 20772080 (doi: 10.1029/2000GL012745)

Engelhardt M, Schuler TV and Andreassen LM (2015) Sensitivities of glacier mass balance and runoff to climate perturbations in Norway. Ann. Glac., 56(70), 79-88 (doi: 10.3189/ 2015AoG70A004)

Flato G and others (2014) Evaluation of climate models. 741-866.

Fleig A and 7 others (2013) Norwegian Hydrological Reference Dataset for climate change studies. NVE Report, 2-2013.

Frankignoul C and Hasselmann K (1977) Stochastic climate models, Part II Application to sea-surface temperature anomalies and thermocline variability. Tellus, 29(4), 289-305 (doi: 10.3402/ tellusa.v29i4.11362)

Guan X, Huang J, Guo R and Lin P (2015) The role of dynamically induced variability in the recent warming trend slowdown over the Northern Hemisphere. Sci. Rep., 5, 12669 (doi: 10.1038/ srep12669)

Hahn L, Ummenhofer CC and Kwon YO (2018) North Atlantic natural variability modulates emergence of widespread Greenland melt in a warming climate. Geophys. Res. Lett., 45 (17), 9171-9178 (doi: 10.1029/2018GL079682)

Hasselmann K (1976) Stochastic climate models part I. Theory. Tellus, 28(6), 473-485 (doi: 10.3402/tellusa.v28i6.11316)

Hawkins E and Sutton R (2009) The potential to narrow uncertainty in regional climate predictions. Bull. Amer. Meteor. Soc., 90(8), 1095-1107 (doi: 10.1175/2009BAMS2607.1)

Holmlund P and Jansson P (1999) The tarfala mass balance programme. Geografiska Annaler: Series A, Physical Geography, 81(4), 621-631.

Hurrell JW (1995) Decadal trends in the North Atlantic Oscillation: regional temperatures and precipitation. Science, 269(5224), 676-679 (doi: 10.1126/science.269.5224.676)

Hurrell JW and Deser C (2010) North Atlantic climate variability: the role of the North Atlantic Oscillation. J. Mar. Syst., 79(3-4), 231244 (doi: 10.1016/j.jmarsys.2008.11.026) 
Hurrell JW, Kushnir Y, Ottersen G and Visbeck M (2003) An overview of the North Atlantic oscillation. Amer. Geophys. Union, 134, 1-35.

Huss M, Hock R, Bauder A and Funk M (2010a) 100-year glacier mass changes in the Swiss Alps linked to the Atlantic Multidecadal Oscillation. Geophys. Res. Lett., 37(10), L10501 (doi: 10.1029/2010GL042616)

Huss M, Hock R, Bauder A and Funk M (2010b) Reply to the Comment of Leclercq et al. on "100-year mass changes in the Swiss Alps linked to the Atlantic Multidecadal Oscillation". Cryosphere Dis., 4, 2587-2592 (doi: 10.5194/tcd-4-2587-2010)

Kalnay E and 21 others (1996) The NCEP/NCAR 40-year reanalysis project. Bull. Amer. Meteor. Soc., 77(3), 437-471 (doi: 10.1175/1520-0477(1996)077<0437:TNYRP>2.0.CO;2)

Kjøllmoen B, Andreassen LM, Elvehøy $\mathrm{H}$, Jackson $\mathrm{M}$ and Melvold $\mathrm{K}$ (2017) Glaciological investigations in Norway 2016. NVE Report, 76, 95.

Knight JR, Folland CK and Scaife AA (2006) Climate impacts of the Atlantic Multidecadal Oscillation, Geophys. Res. Lett., 33(17), L17706 (doi: 10.1029/2006GL026242)

Latif M and Barnett TP (1994) Causes of decadal climate variability over the North Pacific and North America. Science, 266(5185), 634-637 (doi: 10.1126/science.266.5185.634)

Leclercq P, Van de Wal R and Oerlemans J (2010) Comment on "100year mass changes in the Swiss Alps linked to the Atlantic Multidecadal Oscillation" by Matthias Huss et al. (2010). Cryosphere Dis., 4(4), 2475-2481 (doi: 10.5194/tcd-4-2475-2010)

Lehner F, Deser C and Terray L (2017) Toward a new estimate of "time of emergence" of anthropogenic warming: insights from dynamical adjustment and a large initial-condition model ensemble. J. Clim., 30(19), 7739-7756 (doi: 10.1175/JCLI-D16-0792.1)

Leith C (1973) The standard error of time-average estimates of climatic means. J. Appl. Meteorol. Climatol., 12(6), 1066-1069 (doi: 10.1175/1520-0450(1973)012<1066:TSEOTA > 2.0.CO;2)

Lettenmaier DP (1976) Detection of trends in water quality data from records with dependent observations. Water Resour. Res., 12(5), 1037-1046 (doi: 10.1029/WR012i005p01037)

Li F, Orsolini YJ, Wang H, Gao Y and He S (2018) Atlantic Multidecadal Oscillation modulates the impacts of Arctic sea ice decline. Geophys. Res. Lett., 45(5), 2497-2506 (doi: 10.1002/2017GL076210)

Luterbacher J, Dietrich D, Xoplaki E, Grosjean M and Wanner H (2004) European seasonal and annual temperature variability, trends, and extremes since 1500. Science, 303(5663), 14991503 (doi: 10.1126/science.1093877)

Mackintosh AN and 5 others (2017) Regional cooling caused recent New Zealand glacier advances in a period of global warming. Nat. Commun., 8, 14202 (doi: 10.1038/ncomms14202)

Marshall J and 9 others (2001) North Atlantic climate variability: phenomena, impacts and mechanisms. Int. J. Climatol., 21(15), 1863-1898 (doi: 10.1002/joc.693)

Marzeion B and Nesje A (2012) Spatial patterns of North Atlantic Oscillation influence on mass balance variability of European glaciers. Cryosphere, 6(3), 661-673 (doi: 10.5194/tc-6-661-2012)

Marzeion B, Cogley JG, Richter K and Parkes D (2014) Attribution of global glacier mass loss to anthropogenic and natural causes. Science, 345(6199), 919-921 (doi: 10.1126/science.1254702)

McCabe Jr GJ and Fountain AG (1995) Relations between atmospheric circulation and mass balance of South Cascade Glacier, Washington, USA. Arct. Antarct. Alp. Res., 27(3), 226-233 (doi: 10.2307/1551953)

Medwedeff WG and Roe GH (2017) Trends and variability in the global dataset of glacier mass balance. Clim. Dyn., 48(9-10), 3085-3097 (doi: 10.1007/s00382-016-3253-x)

Miles MW and 5 others (2014) A signal of persistent Atlantic multidecadal variability in Arctic sea ice. Geophys. Res. Lett., 41(2), 463-469 (doi: 10.1002/2013GL058084)

Mutz S, Paeth H and Winkler S (2016) Modelling of future mass balance changes of Norwegian glaciers by application of a dynamical-statistical model. Clim. Dyn., 46(5-6), 1581-1597 (doi: 10.1007/s00382-015-2663-5)

Nesje A, Lie Ø and Dahl SO (2000) Is the North Atlantic Oscillation reflected in Scandinavian glacier mass balance records?. J. Quat. Sci., 15(6), 587-601 (doi: 10.1002/1099-1417(200009)15: 6<587::AID-JQS533>3.0.CO;2-2)

Nesje A, Bakke J, Dahl SO, Lie Ø and Matthews JA (2008) Norwegian mountain glaciers in the past, present and future. Glob. Planet. Change, 60(1-2), 10-27 (doi: 10.1016/j.gloplacha.2006.08.004)

NPI (2017) Austre Brøggerbreen, Midtre Lovénbreen, and Kongsvegen mass-balance time series. MOSJ, url: http://www. mosj.no/en/climate/land/mass-balance-glaciers.html

Oerlemans J (2005) Extracting a climate signal from 169 glacier records. Science, 308(5722), 675-677 (doi: 10.1126/ science.1107046)

O'Reilly CH, Huber M, Woollings T and Zanna L (2016) The signature of low-frequency oceanic forcing in the Atlantic Multidecadal Oscillation. Geophys. Res. Lett., 43(6), 28102818 (doi: 10.1002/2016GL067925)

Pohjola VA and Rogers JC (1997) Atmospheric circulation and variations in Scandinavian glacier mass balance. Quat. Res., 47 (1), 29-36 (doi: 10.1006/qres.1996.1859)

Rasmussen LA (2007) Spatial extent of influence on glacier mass balance of north atlantic circulation indices. Terra Glacialis, 10, 43-758.

Rasmussen L and Conway $\mathrm{H}$ (2005) Influence of upper-air conditions on glaciers in Scandinavia. Ann. Glac., 42, 402-408 (doi: 10.3189/172756405781812727)

Rayner NA and 7 others (2003) Global analyses of sea surface temperature, sea ice, and night marine air temperature since the late nineteenth century. J. Geophys. Res., 108(D14) (doi: 10.1029/ 2002JD002670)

RGI Consortium (2017) Randolph Glacier Inventory - A Dataset of Global Glacier Outlines: Version 6.0: Technical Report, Global Land Ice Measurements from Space, Colorado, USA. Digital Media, doi: 10.7265/N5-RGI-60

Rodwell MJ, Rowell DP and Folland CK (1999) Oceanic forcing of the wintertime North Atlantic Oscillation and European climate. Nature, 398(6725), 320 (doi: 10.1038/18648)

Roe GH (2011) What do glaciers tell us about climate variability and climate change?. J. Glac., 57(203), 567-578 (doi: 10.3189/ 002214311796905640)

Roe GH, Baker MB and Herla F (2017) Centennial glacier retreat as categorical evidence of regional climate change. Nat. Geosci., 10(2), 95 (doi: 10.1038/ngeo2863)

Siler N, Proistosescu C and Po-Chedley S (2019) Natural Variability Has Slowed the Decline in Western US Snowpack Since the 1980s. Geophys. Res. Lett., 46(1), 346-355 (doi: 10.1029/2018GL081080)

Smoliak BV, Wallace JM, Stoelinga MT and Mitchell TP (2010) Application of partial least squares regression to the diagnosis of year-to-year variations in Pacific Northwest snowpack and Atlantic hurricanes. Geophys. Res. Lett., 37(3), L03801 (doi: 10.1029/2009GL041478)

Smoliak BV, Wallace JM, Lin P and Fu Q (2015) Dynamical adjustment of the Northern Hemisphere surface air temperature field: methodology and application to observations. J. Clim., 28(4), 1613-1629 (doi: 10.1175/JCLI-D-14-00111.1)

Stocker T (2014) Climate change 2013: the physical science basis: Working Group I contribution to the Fifth assessment report of the Intergovernmental Panel on Climate Change.

Sutton RT and Hodson DL (2005) Atlantic Ocean forcing of North American and European summer climate. Science, 309(5731), 115-118 (doi: 10.1126/science.1109496)

Trachsel M and Nesje A (2015) Modelling annual mass balances of eight Scandinavian glaciers using statistical models. Cryosphere, 9, 1401-1414 (doi: 10.5194/tc-9-1401-2015)

Visbeck MH, Hurrell JW, Polvani L and Cullen HM (2001) The North Atlantic Oscillation: past, present, and future. Proc. Natl. Acad. Sci., 98(23), 12876-12877 (doi: 10.1073/ pnas.231391598) 
Wallace JM, Fu Q, Smoliak BV, Lin P and Johanson CM (2012) Simulated versus observed patterns of warming over the extratropical Northern Hemisphere continents during the cold season. Proc. Natl. Acad. Sci., 109(36), 14337-14342 (doi: 10.1073/pnas.1204875109)

WGMS (2017) Fluctuations of glaciers database. World Glacier Monitoring Service, Zurich, Switzerland (doi: 10.5904/wgmsfog-2017-10

Wigley T and Raper S (1990) Natural variability of the climate system and detection of the greenhouse effect. Nature, 344 (6264), 324 (doi: 10.1038/344324a0)

Wills RC, Schneider T, Wallace JM, Battisti DS and Hartmann DL (2018) Disentangling global warming, multidecadal variability, and El Niño in Pacific temperatures. Geophys. Res. Lett., 45(5), 2487-2496 (doi: 10.1002/2017GL076327)

Wills RC, Armour KC, Battisti DS and Hartmann DL (2019) Oceanatmosphere dynamical coupling fundamental to the Atlantic Multidecadal Oscillation. J. Clim., 32, 251-272 (doi: 10.1175/ JCLI-D-18-0269.1)

Wold S, Sjöström M and Eriksson L (2001) PLS-regression: a basic tool of chemometrics. Chemometr. Intell. Lab. Syst., 58(2), 109-130 (doi: 10.1016/S0169-7439(01)00155-1)

Zemp $M$ and others (2015) Historically unprecedented global glacier decline in the early 21st century. J. Glac., 61(228), 745-762 (doi: 10.3189/2015JoG15J017)

\section{APPENDIX A}

Here, we provide additional details on PLS-based dynamical adjustment. As described in the main text, PLS regression is a matrix analysis method that identifies patterns in a predictor, $\mathbf{X}$, optimized to explain variance in a variable of interest, $\mathbf{Y}$, called the predictand. For each adjustment in this study, $\mathbf{X}$ is a spatiotemporal SLP or SST field and $\mathbf{Y}$ is an individual seasonal mass-balance time series. If $n$ is the number of years in the glacier mass-balance record and $m$ is the number of predictor grid points, then $\mathbf{X}$ is a $n \times m$ matrix and $\mathbf{Y}$ is a $n \times 1$ vector. Both $\mathbf{X}$ and $\mathbf{Y}$ are standardized to zero mean and unit variance. The spatial pattern $\mathbf{W}$ is correlation map using the temporally detrended variables (denoted by $\mathbf{X}^{\prime}$ and $\left.\mathbf{Y}^{\prime}\right)$ :

$$
\mathbf{W}=\frac{1}{n-1} \mathbf{X}^{\prime \top} \mathbf{Y}^{\prime}
$$

If $\mathbf{W}$ is reshaped back into grid (lat $\times$ lon) dimensions, it yields the correlation maps shown in Figs $2-5$. Next, $\mathbf{X}$ is projected onto $\left\langle\mathbf{W}_{\mathrm{c}}\right\rangle$, where the brackets denote normalization and $\mathbf{W}_{\mathrm{c}}$ is $\mathbf{W}$ area-weighted by the cosine of latitude:

$$
\mathbf{t}=\mathbf{X}\left\langle\mathbf{W}_{\mathrm{c}}\right\rangle,
$$

where $\mathbf{t}$ is a temporal index (with dimensions $n \times 1$ ) that expresses the variations of the predictor field constrained by its correlation with mass-balance variability. The regression coefficients are, for $\mathbf{X}$, the vector:

$$
\mathbf{P}=\mathbf{X}^{\top}\langle\mathbf{t}\rangle
$$

and for $\mathbf{Y}$, the scalar:

$$
\beta=\left\langle\mathbf{t}^{\top}\right\rangle \mathbf{Y}
$$

Using $\mathbf{P}$ and $\beta$, $\mathbf{t}$ is then regressed out of $\mathbf{X}$ and $\mathbf{Y}$, which yields the dynamically adjusted variables:

$$
\mathbf{X}_{\mathrm{adj}}=\mathbf{X}-\mathbf{t} \mathbf{P}^{\top} \text { and } \mathbf{Y}_{\text {adj }}=\mathbf{Y}-\beta \mathbf{t}
$$

As noted in Section 3, the regression is then repeated using $\mathbf{X}_{\text {adj }}$ and $\mathbf{Y}_{\text {adj }}$ as inputs, yielding a series of indices $\mathbf{t}_{1}, \mathbf{t}_{2}, \ldots, \mathbf{t}_{\boldsymbol{i}}$ until further iterations fail to explain appreciable amounts of variance. For each iteration, the variance explained by $\mathbf{t}_{i}$ is given by:

$$
\frac{\mathbf{P}_{i}^{\top} \mathbf{P}_{i}}{\sum_{m} \sum_{n}\left|\mathbf{X}_{m n}\right|^{2}} \text { for } \mathbf{X} \text { and } \frac{\beta_{i}^{2}}{\sum_{n}\left|\mathbf{Y}_{n}\right|^{2}} \text { for } \mathbf{Y} .
$$

